\title{
Molecular-Dynamics Study on the Impact Energy Release Characteristics of Fe-Al Energetic Jets
}

\author{
Qiang Li ${ }^{1}\left(\mathbb{D}\right.$, Chunlan Jiang ${ }^{2, * \mathbb{C}}$ and $\mathrm{Ye} \mathrm{Du}^{1}$ \\ 1 College of Mechatronic Engineering, North University of China, Taiyuan 030051, China; \\ liqiang1170@126.com (Q.L.); dy_ibc@nuc.edu.cn (Y.D.) \\ 2 State Key Laboratory of Explosion Science and Technology, Beijing Institute of Technology, \\ Beijing 100081, China \\ * Correspondence: jiangchunwh@bit.edu.cn
}

Citation: Li, Q.; Jiang, C.; Du, Y. Molecular-Dynamics Study on the Impact Energy Release

Characteristics of Fe-Al Energetic Jets.

Materials 2021, 14, 5249. https://

doi.org/10.3390/ma14185249

Academic Editor: Tomasz Sadowski

Received: 30 July 2021

Accepted: 7 September 2021

Published: 13 September 2021

Publisher's Note: MDPI stays neutral with regard to jurisdictional claims in published maps and institutional affiliations.

Copyright: (c) 2021 by the authors. Licensee MDPI, Basel, Switzerland. This article is an open access article distributed under the terms and conditions of the Creative Commons Attribution (CC BY) license (https:/ / creativecommons.org/licenses/by/ $4.0 /)$.

\begin{abstract}
Fe}-\mathrm{Al}$ energetic material releases a large amount of energy under impact loading; therefore, it can replace traditional materials and be used in new weapons. This paper introduces the macroscopic experiment and microscopic molecular-dynamics simulation research on the energy release characteristics of $\mathrm{Fe}-\mathrm{Al}$ energetic jets under impact loading. A macroscopic dynamic energy acquisition test system was established to quantitatively obtain the composition of $\mathrm{Fe}-\mathrm{Al}$ energetic jet reaction products. A momentum mirror impacting the $\mathrm{Fe}-\mathrm{Al}$ particle molecular model was established and the microstructure evolution and impact thermodynamic response of Fe-Al particles under impact loading were analyzed. The mechanism of multi-scale shock-induced chemical reaction of Fe-Al energetic jets is discussed. The results show that the difference in velocity between $\mathrm{Fe}$ and $\mathrm{Al}$ atoms at the shock wave fronts is the cause of the shock-induced reaction; when the impact strength is low, the $\mathrm{Al}$ particles are disordered and amorphous, while the Fe particles remain in their original state and only the oxidation reaction of $\mathrm{Al}$ and a small amount intermetallic compound reaction occur. With the increase of impact strength, Al particles and Fe particles are completely disordered and amorphized in a high-temperature and high-pressure environment, fully mixed and penetrated. The temperature of the system rises rapidly, due to a violent thermite reaction, and the energy released by the jet shows an increasing trend; there is an impact intensity threshold, so that the jet release energy reaches the upper limit.
\end{abstract}

Keywords: energetic jets; impact loading; energy release; molecular dynamics; multi-scale

\section{Introduction}

The large amounts of energy released by energetic materials enables the replacement of conventional materials in new types of weapons [1-3]. Among them, the rapid reaction phenomenon and high exothermicity between the shock-induced chemical reaction (SICR) of the $\mathrm{Fe}-\mathrm{Al}$ composite energetic material attract an increasing number of researchers [4-7]. The material is insensitive to friction, combustion and explosion under normal conditions. However, under a strong impact load, the impact energy drives the Fe phase and the active Al phase to react violently, releasing a large amount of energy. Therefore, applying this energetic material to the liner can form an energetic jet and greatly increase the damage power [8].

Recently, substantial progress had been made in the field of preparation and impact deformation of Fe-Al energetic composite materials. Du et al. [9] coated nano Al powder based on the chemical liquid deposition method and chemical vapor deposition method and prepared a new type of metal Fe/Alp composite powder, which improved the stability and energy release efficiency of nano Al powder. Airiskallio et al. [10] experimentally determined that $\mathrm{Fe}-\mathrm{Al}$ intermetallic compounds have outstanding antioxidant properties. Wang et al. [11] prepared Fe-Al micro/nanocomposite particles with core-shell structures and found that the thermal reactivity of the $\mathrm{Fe}-\mathrm{Al}$ micro/nanocomposite powder was 
significantly higher than that of the raw $\mathrm{Al}$ powder by differential scanning calorimetry (DSC) analysis. Wang et al. [12] studied the influence of composition ratio on the reaction heat of $\mathrm{Fe}-\mathrm{Al}$ energetic materials through DSC scanning and SEM microstructure and optimized the $\mathrm{Fe}-\mathrm{Al}$ composition scheme based on the highest energy release efficiency. Andryushchehko et al. [13] applied a pulsed laser to the surface of an $\mathrm{Fe}-\mathrm{Al}-\mathrm{C}$ alloy containing diamond crystals to form spherical graphite particles with a size of 100-300 $\mu \mathrm{m}$ and obtained the law of the effect of pulsed laser on the surface of $\mathrm{Fe}-\mathrm{Al}-\mathrm{C}$ alloy samples containing diamond crystals. Zamanzade et al. [14] used nanoindentation technology to evaluate the contribution of single vacancy, double vacancy and triple defects of $\mathrm{FeAl}$ intermetallics to investigate the transformation of mechanical properties. The study found that, in samples with double vacancies, compared with single vacancies, the increase in hardness was more obvious.

Understanding the mechanism of the energy released by the $\mathrm{Fe}-\mathrm{Al}$ energetic jet under impact loading is a key link to promote its application. However, limited by testing conditions, observing the macroscopic experimental phenomena is obviously not enough to reveal the mechanism of the material at the micro level. The impact compression experiment has significant limitations in detecting the deformation in the particle mixture and the microscopic details of the large-scale mixing flow. In order to make up for the deficiency of experimental observation methods, scholars try to use molecular-dynamics simulation methods to study the physical phase transition process of Fe-based materials after impact loading. Guo et al. [15] used molecular-dynamics methods to study the structural phase transition of $\mathrm{Fe}-\mathrm{Al}$ materials under high-rate compression loading conditions and analyzed the changes in pressure and temperature with strain during the material loading process. Wang et al. [16] studied the plasticity and phase transition of Fe under high pressure based on the embedded atom model. For the first time, the impact plastic behavior of Fe was observed on the atomic scale. Based on the first principles, Lu et al. [17] conducted a non-equilibrium molecular-dynamics simulation of polycrystalline Fe and obtained the phase transition mechanism of Fe under impact compression. Huang et al. [18] used the non-equilibrium molecular-dynamics method to simulate the shock compression response of a single crystal Fe model with multiple dislocation structures. It is found that under high-intensity impact, plastic deformation in local areas is beneficial to the occurrence of phase transformation. Gunkelmann et al. [19] used the improved potential function of Fe to study the plastic deformation and phase transformation of Fe under impact loading. It was found that plastic changes such as dislocations occurred. Yang et al. [20] analyzed the dependence of the incident energy of deposited atoms on the growth configuration of $\mathrm{Fe}-\mathrm{Al}$ nanoparticles. The impact deposition of $\mathrm{Al}$ (or Fe) atoms on the rhombohedron of $\mathrm{Fe}$ (or the truncated octahedron of $\mathrm{Al}$ ) nanoparticles was investigated by performing a molecular-dynamics simulation using the embedded atom method.

The current research on the SICR of Fe-Al energetic materials is mainly focused on observing the physical microstructure of the static initial and final states of the powder mixture, but the mechanism of the chemical reaction process of the energy release under high strain rate loading is still not clear. This study aims to fill the gap in research on the energy release mechanism of $\mathrm{Fe}-\mathrm{Al}$ energetic materials when applied to jets.

In this paper, by designing energy-harvesting experiments, the impact energy-release characteristics of $\mathrm{Fe}-\mathrm{Al}$ energetic jets under different impact intensities are discussed. Molecular-dynamics simulation methods are used to analyze the impact compression response process and SICR mechanism of $\mathrm{Fe}-\mathrm{Al}$ composites. The research reveals the impact energy-release mechanism of $\mathrm{Fe}-\mathrm{Al}$ energetic jets from the macro-micro multi-scale.

\section{Methods of Simulation}

\subsection{Experimental Design and Scheme}

The Fe-Al energetic jet-dynamic energy-acquisition test system was designed and the impact energy release characteristics of the $\mathrm{Fe}-\mathrm{Al}$ energetic jet were studied by experimental means. By adjusting the thickness of the target plate, the jet was loaded with different 
impact energy. The XRD analysis method was used to observe and test the composition of the residual substance in the container. The field experimental device is shown in Figure 1 and the experimental system is shown in Figure 2. The specific experimental devices and methods of data processing have been elaborated in my previous articles [21] and are not repeated here.

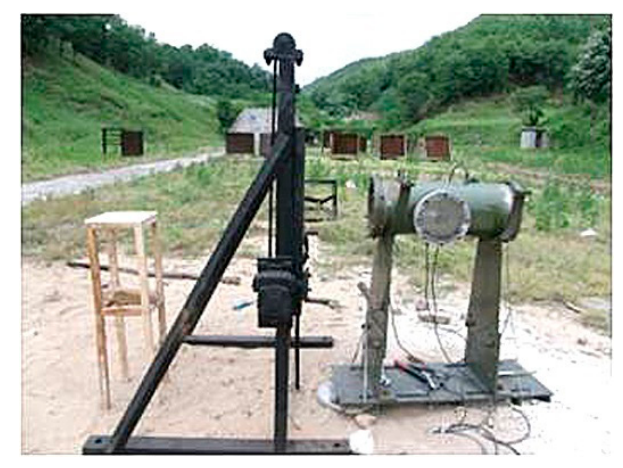

Figure 1. Field experimental device.

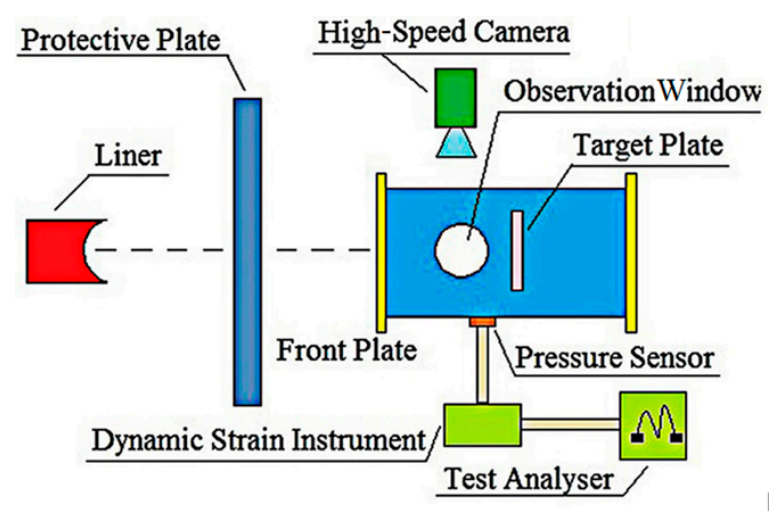

Figure 2. Schematic diagram of the energy acquisition system.

\subsection{Molecular-Dynamics Simulation Method}

To further reveal the mechanism of the macroscopic impact energy-release phenomenon of $\mathrm{Fe}-\mathrm{Al}$ energetic jets, the molecular-dynamics simulation was carried out. The embedded atom method (EAM) proposed by Mendelev et al. and the potential function between $\mathrm{Al}$ and Fe proposed by Eunkoo et al. [22] are used to describe the interaction between $\mathrm{Fe}-\mathrm{Al}$ metal atoms. The LAMMPS molecular-dynamics software is used to simulate the relaxation and shock response process of $\mathrm{Fe}-\mathrm{Al}$ particles. In order to facilitate the homogeneously mixing of Fe-Al particles, spherical Fe particles and spherical Al particles are arranged and stacked according to the cubic crystal structure. In order to facilitate the alternating and uniform mixing of $\mathrm{Fe}-\mathrm{Al}$ particles, the initial unit is established by arranging and stacking spherical Fe particles and spherical Al particles according to the cubic crystal structure [23]. Each unit contains $4 \mathrm{Fe}$ particles and $4 \mathrm{Al}$ particles. The lattice points in the two kinds of particles create single Fe atoms and $\mathrm{Al}$ atoms, respectively, as shown in Figure 3. The initial diameters of Fe particles and Al particles are both $6 \mathrm{~nm}$, the distance between adjacent particles is $0.25 \mathrm{~nm}$ and the unit size is $12.5 \times 12.5 \times 12.5 \mathrm{~nm}$. It is expanded 1 time along the $x$-axis direction, 1 time along the $y$-axis direction and 10 times along the $z$-axis direction, constructing a particle mixing system containing 1.04 million atoms. 


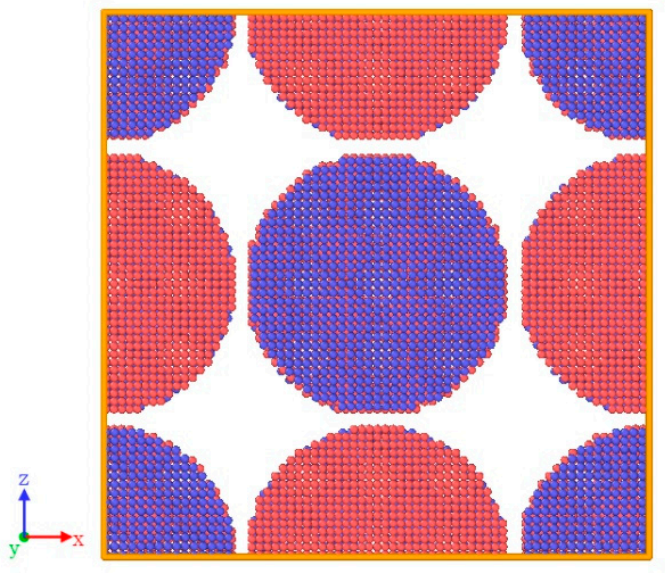

(a)

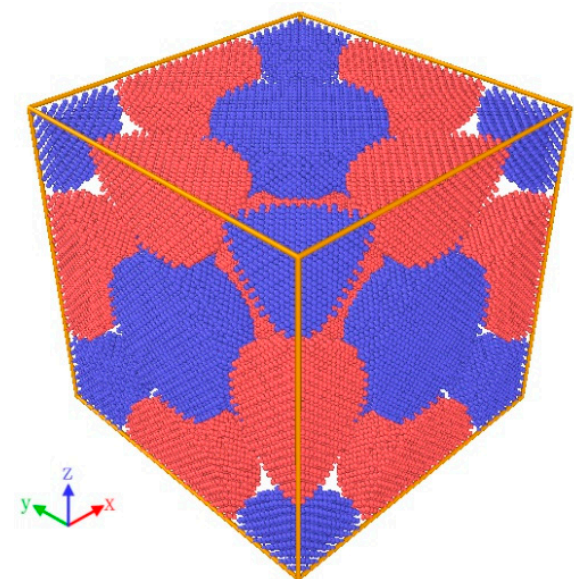

(b)

Figure 3. The model of the initial unit (Fe atoms are colored in red and $\mathrm{Al}$ atoms are colored in blue) (a) Front view (b) Oblique view.

According to previous studies, the energetic-type cover produces an impact temperature rise and a plastic temperature rise during the process of forming an energetic jet after undergoing a process of crushing and stretching and the final temperature can reach $700 \mathrm{~K}$ [24]. In order to simulate the state of the energetic jet accurately before it hits the target plate, the initial case is relaxed at $700 \mathrm{~K}$. First, the model is relaxed under the conjugate gradient method to minimize the energy, then the temperature is maintained at $700 \mathrm{~K}$ under the isothermal-isobaric ensemble (NPT) and, finally, under the microcanonical ensemble (NVE), for 300 ps. The relaxed model is used as the initial state of impact simulation. The method of "momentum mirror" is used to create an infinite mass piston, which moves to the $\mathrm{Z}$ axis at a speed of $\mathrm{Up}$ and applies impact loading on the $\mathrm{Fe}-\mathrm{Al}$ mixed particle model. As shown in Figure 4, the loading speed range is $400-4000 \mathrm{~m} / \mathrm{s}$. The particles obtain different impact energy by changing the impact velocity and the simulation results obtained are compared with the macroscopic experiment of the corresponding impact energy. The entire impact process is carried out in the NVE with a time step of $100 \mathrm{ps}$. A free boundary is applied on the $\mathrm{Z}$ axis and periodic boundary conditions are applied in the other directions. The software OVITO (Version 3.4.4) is used to visualize and analyze the simulation results.
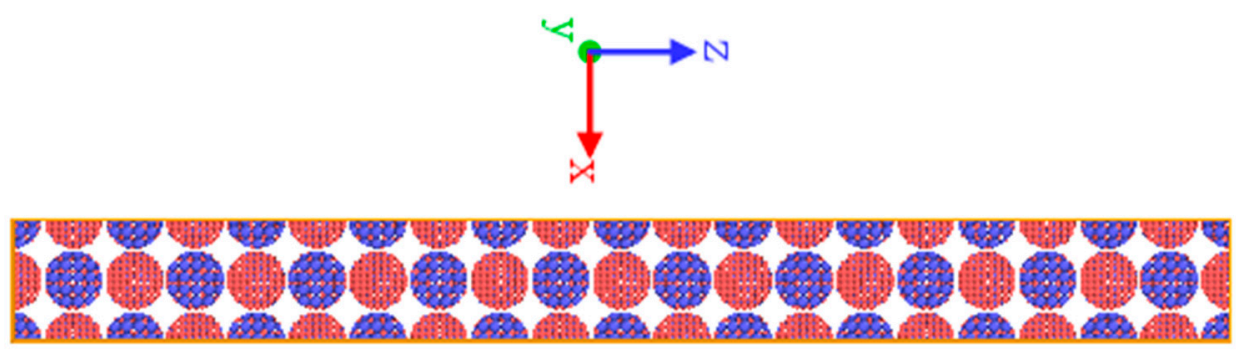

Figure 4. "Momentum mirror" impact model.

\section{Results and Discussion}

\subsection{Impact Reaction Product Composition}

Figure 5 shows the XRD patterns of the recovered products. The XRD detection method refers to the paper by Gorji N.E. [25]. 

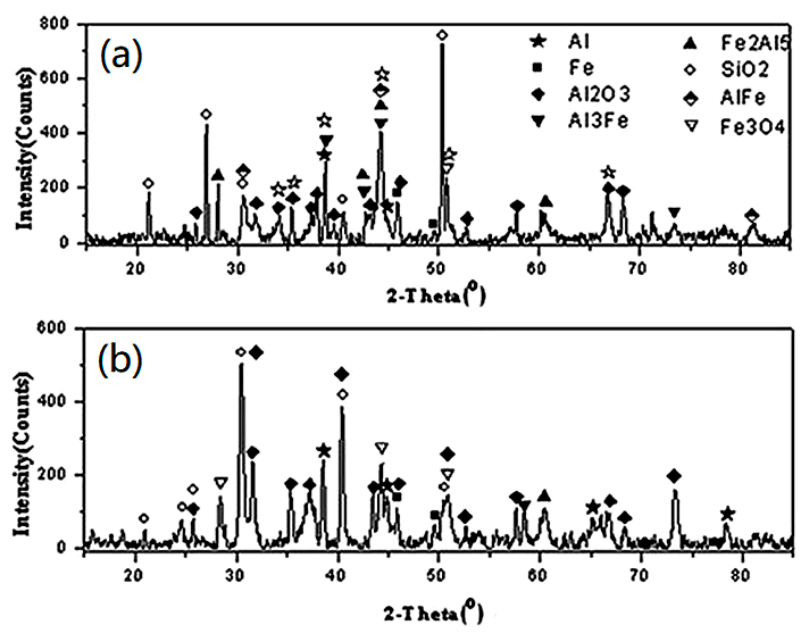

Figure 5. XRD patterns of the reaction products with different thickness targets: (a) 2-mm target; (b) 5-mm target. This picture is taken from "Li, Q.; Du, Y. Experimental Study on the Energy-Release Characteristics of Fine-Grained Fe/Al Energetic Jets under Impact Loading. Materials 2019, 12, 3317" [21].

It can be seen, from Figure 5, that, in the low-impact strength-recovered products, the elemental $\mathrm{Al}$ content is the highest. Additionally, small amounts of intermetallic composites are found and no substantial amount of $\mathrm{Fe}_{3} \mathrm{O}_{4}$ is formed, indicating that the $\mathrm{Al}$ oxidation and $\mathrm{Fe}-\mathrm{Al}$ intercalation reactions occur mainly under low-impact strength conditions. A high-impact strength results in the recovery of only a small amount of metallic elements and composites, most of which are $\mathrm{Al}_{2} \mathrm{O}_{3}$ and $\mathrm{Fe}_{3} \mathrm{O}_{4}$, indicating a great quantity of oxidative reactions and thermite reaction of energetic substances in $\mathrm{Fe}-\mathrm{Al}$ jet is induced by high-impact strength, as shown in Equations (1)-(3). The results shown in Figure 5 explain the phenomenon of more energy released by a Fe-Al energetic jet under high-impact strength from mesoscopic scale.

$$
\begin{gathered}
\mathrm{Al}+3 / 4 \mathrm{O}_{2}=1 / 2 \mathrm{Al}_{2} \mathrm{O}_{3} \\
\mathrm{Fe}+2 / 3 \mathrm{O}_{2}=1 / 3 \mathrm{Fe}_{3} \mathrm{O}_{4} \\
\mathrm{Al}+3 / 8 \mathrm{Fe}_{3} \mathrm{O}_{4}=9 / 8 \mathrm{Fe}+1 / 2 \mathrm{Al}_{2} \mathrm{O}_{3}
\end{gathered}
$$

\subsection{Evolution of Particle Microstructure}

The regular pattern of temperature change obtained by the unit model with $700 \mathrm{~K}$ temperature relaxation is shown in Figure 6. The temperature increased slightly by $25 \mathrm{~K}$ within 200 ps. It shows that the Fe-Al energetic material is in a metastable state after forming a jet and the spontaneous reaction occurs slowly.

The atoms are colored with local von Mises stress and the stress distribution during the relaxation process is shown in Figure 7. It is found that when the relaxation lasts for $30 \mathrm{ps}$, as the temperature increases, the kinetic energy of the particles increases and the particles of the two elements squeeze and collide at the interface, with a stress value of $15 \mathrm{GPa}$. In contrast, little change occurs for the stress in the center of particle. When the relaxation lasts for 200 ps, the boundary between the particles of the two elements is severely deformed and the gap between the particles is significantly reduced or it even disappears. The atoms in the inner regions of the particles also begin to squeeze each other, forming a GPa-level stress, and the interpenetration of atoms of different elements appears at the boundary. It is speculated that, during the jet-formation stage, an intermetallic compound reaction occurs between Fe and $\mathrm{Al}$ atoms, but most of the material activity is still maintained. Due to the low-yield strength of Al particles, they can no longer maintain a spherical shape under extrusion and collision, so the internal stress of the particles is not uniformly distributed. 


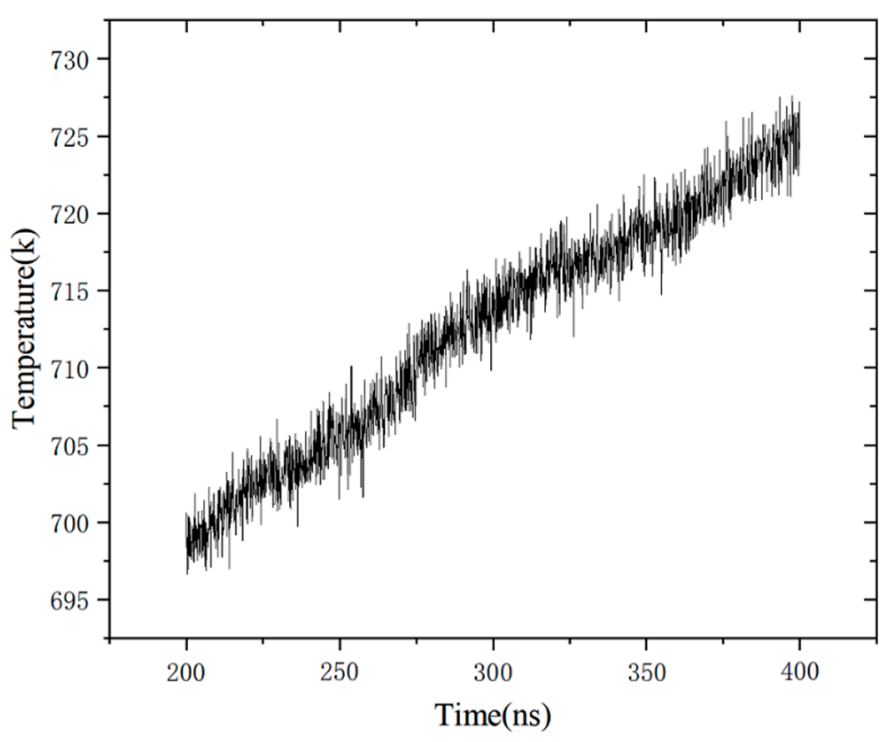

Figure 6. Regular pattern of temperature changed after relaxation.

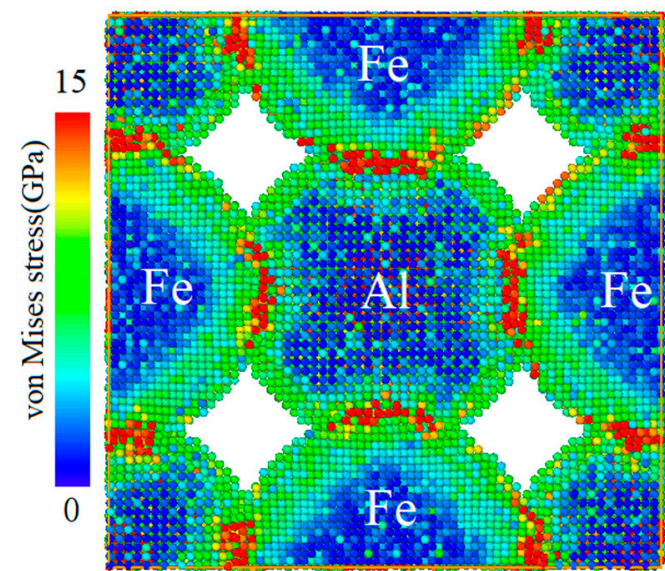

(a) $30 \mathrm{ps}$

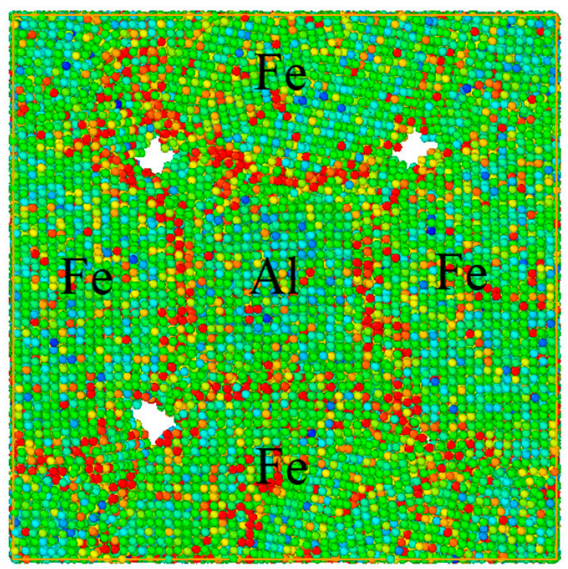

(b) $200 \mathrm{ps}$

Figure 7. Stress distribution during model relaxation.

The microstructure of the unit after relaxation is shown in Figure 8. Obvious strip defects can be found inside the Fe particles, but no metastable phase of FCC. A small amount of $\mathrm{HCP}$ phase transition can be found inside the Al particles, forming several asymmetric slip surfaces, as indicated by the arrows in Figure 8. The relaxed configuration is similar to the state of the porous material after impact compression. It shows that, even if there is no external force, when the high-temperature jet is formed, the $\mathrm{Al}$ and Fe particles form uneven local stress during the extrusion process, resulting in a large number of lattice defects.

Figure 9 shows the morphology of $\mathrm{Fe}-\mathrm{Al}$ particles under different impact strengths. When the impact velocity is less than $800 \mathrm{~m} / \mathrm{s}$, as the shock wave propagates in the model, the $\mathrm{Al}$ particles are severely deformed and fill the pores with the increasing density of the overall particle. This is because, at a low-impact velocity, the relaxation temperature $(725 \mathrm{~K})$ plus the impact temperature rise exceeds the melting point of $\mathrm{Al}$, forcing the $\mathrm{Al}$ particles in a molten state. The pre-existing gap defects between particles accelerate the flow and deformation of $\mathrm{Al}$ particles. The melting point of iron particles is higher than that of $\mathrm{Al}$, so they do not deform much at low-impact speeds. In contrast, little change occurs in the morphology of Fe particles. When the impact velocity is greater than $1200 \mathrm{~m} / \mathrm{s}$, the shape of $\mathrm{Fe}$ and $\mathrm{Al}$ particles changes from a sphere to an ellipsoid at the front of the shock wave. The greater the impact velocity, the more serious the deformation. As the 
impact velocity increases behind the wave front, the $\mathrm{Al}$ particles and Fe particles become increasingly disordered with drastic plastic deformation, permeating and fusing with each other.

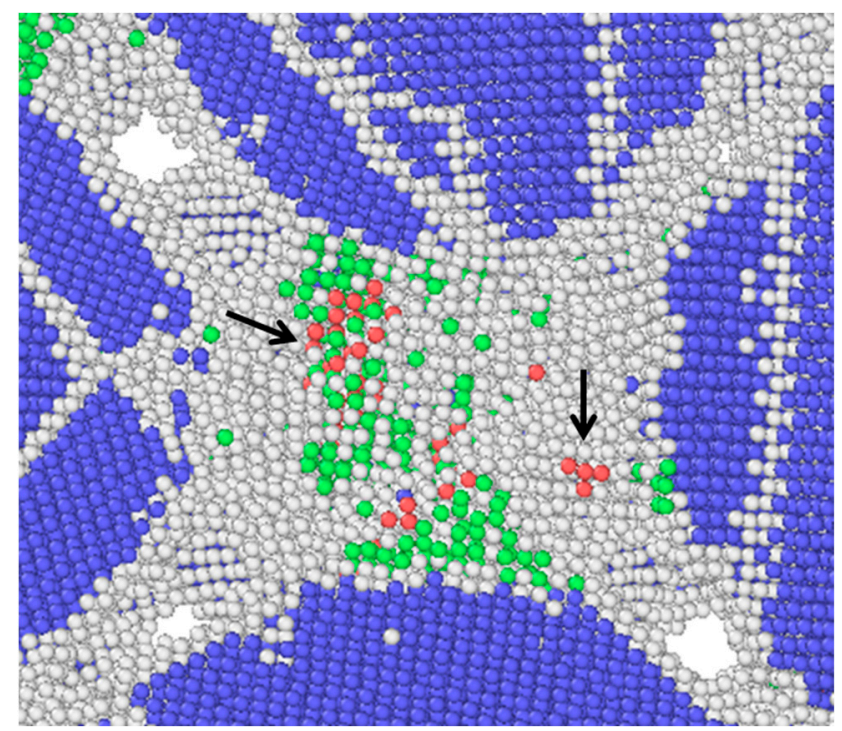

Figure 8. Microstructure after relaxation (FCC, BCC, HCP and unclassified atoms are colored in green, bule, red and white, respectively).

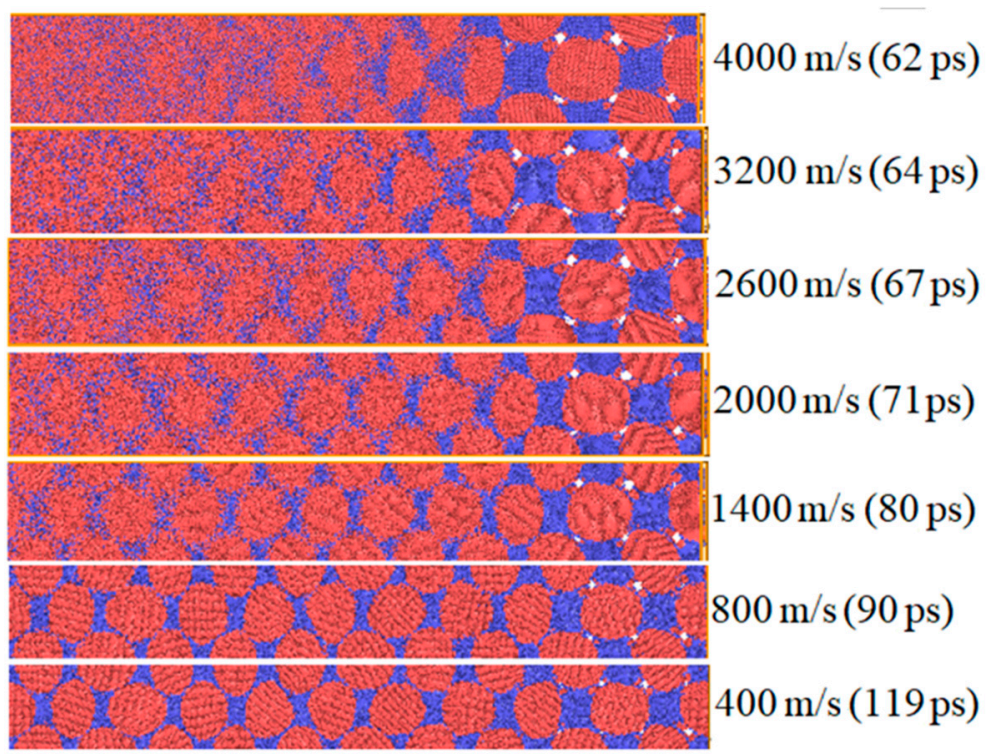

Figure 9. Particle morphology under different impact strength.

In order to compare the deformation behaviors of particles during impact compression, the deformation states of the two particles are extracted separately along the $\mathrm{Z}$ axis, as shown in Figure 10. When the impact velocity is $800 \mathrm{~m} / \mathrm{s}$, the deformation extent of $\mathrm{Al}$ particles is greater than that of Fe particles. Al particles show a morphology compressed by shock waves, but still remain an ordered arrangement. The morphology of Fe particles is changed from sphere to ellipsoid. When the impact velocity is $2000 \mathrm{~m} / \mathrm{s}$, the Al particles are driven by high stress to form obvious high-speed jets on both sides, forming local area deformation. The ejected $\mathrm{Al}$ atoms penetrate through the Fe particles and reach the adjacent $\mathrm{Al}$ particles, which induces the activation of the $\mathrm{Al} / \mathrm{Fe}$ interface, which is more conducive to the occurrence of chemical reactions. The Fe particles do not form an obvious jet, but there is still a considerable amount of Fe atoms peeled off the surface of the particles 
and fused with the adjacent $\mathrm{Al}$ particles, showing that the morphology of Fe particles is obviously loose. When the impact velocity is $4000 \mathrm{~m} / \mathrm{s}$, both Al and Fe are severely disordered and amorphized and the original morphology cannot be identified. The moving distance of the atoms increases significantly and the two kinds of atoms are deeply fused, which are the conditions to induce chemical reactions.

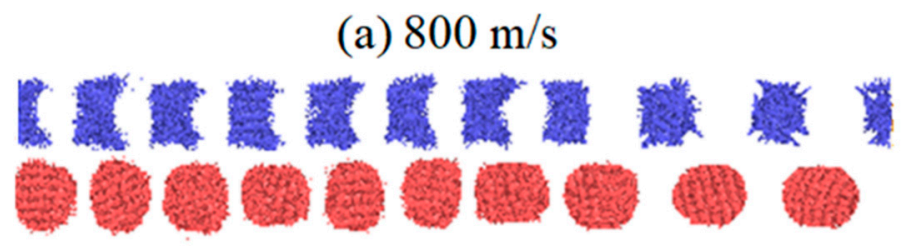

(b) $2000 \mathrm{~m} / \mathrm{s}$

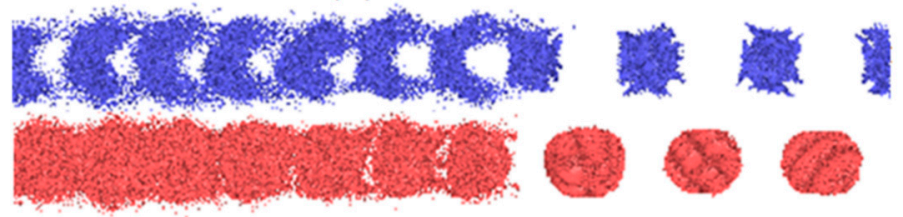

(c) $4000 \mathrm{~m} / \mathrm{s}$

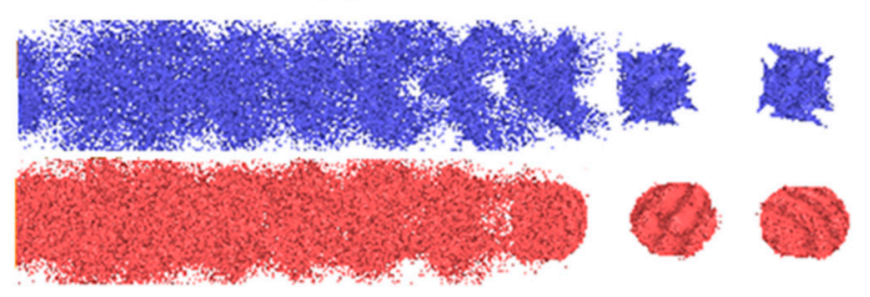

Figure 10. Deformation states of two particles under different impact speeds (Fe particles are colored in red and $\mathrm{Al}$ particles are colored in blue).

Figure 11 shows the microstructure of wave fronts at different impact velocities. It can be found that, when the impact velocity is less than $400 \mathrm{~m} / \mathrm{s}$, except for a small part of the Al particles in the impacted area which maintain the FCC structure, the rest become amorphous. The slip planes that appeared during relaxation basically disappear and the transition from slip to twinning does not occur. A certain number of disordered atoms appears inside Fe particles, but most of them maintain the BCC structure. This is because the particle temperature is lower than $1200 \mathrm{~K}$, as shown in Figure 18 (mentioned below), which does not meet the conditions for forming the $\gamma$-Fe FCC structure. As the impact velocity increases to $1400 \mathrm{~m} / \mathrm{s}$, the Al particles are further disordered and the FCC structure basically disappears. A large number of defects appears in the Fe particles and only about half of the BCC structure remains. When the impact velocity is greater than $2000 \mathrm{~m} / \mathrm{s}$, the amorphous transformation of Fe is completed in the narrow area of the shock-wave front and the impact area is basically completely amorphous. Comparing the particle morphology under different impact strengths (as shown in Figure 9), it can be found that, when the impact velocity is greater than $1400 \mathrm{~m} / \mathrm{s}$, first, the Al particles melt because the temperature exceeds the melting point and the liquid Al quickly fills the defect spaces between the particles. Next, part of the Fe particles transforms into an amorphous state (the number of transformations is proportional to the impact speed), which is further refined and mixed with liquid $\mathrm{Al}$ atoms. The mixing process is different from the atomic secondlevel slow diffusion under static conditions, but, when the shock wave front is loaded, the two elements are mixed at an ultra-fast ps level. It shows that the amorphization of Fe particles under impact loading can greatly increase the reaction rate, which verifies the rationality of the hypothesis of high diffusion rate in SICR [26]. 

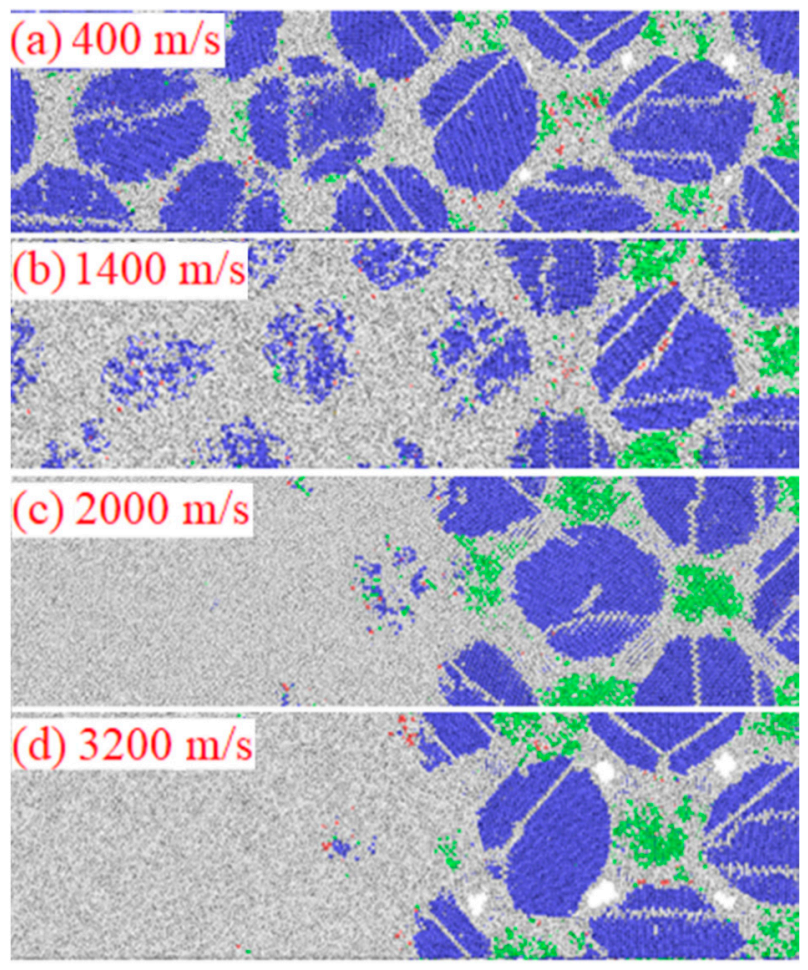

Figure 11. Microstructure of wave fronts at different impact velocities.

\subsection{Impact Response}

Figure 12 shows the particle velocity waveforms at different moments when the impact velocity is $1400 \mathrm{~m} / \mathrm{s}$. Since there are differences in the types and speed of motion of atoms in the same sub-regions, this figure refers to the average speed in the sub-regions. It can be seen that the particle velocity in the impact loading area presents periodic oscillations. Under the same impact velocity, the particle velocity of the shock-wave front passing through different areas has basically the same changing rule. The particle velocity increases rapidly where the wave front reaches and the particle velocity at a certain distance behind the wavefront is higher than when the front passes by. It shows that the Al-Fe mixed particles induce a reaction after being loaded by shock, release energy and accelerate the movement of the particles. As the impact loading speed increases, the particle velocity shows an increasing trend, as shown in Figure 13.

Since the particle velocity dispersion (PVD) is a possible mechanism to explain the $\mathrm{SICR}$, it is necessary to extract the particle velocities of $\mathrm{Al}$ particles and Fe particles separately for comparison. As shown in Figure 14, at a certain distance behind the wave front, the particle velocities of the two elements are basically the same, but at the front of the shock wave, there is a difference in velocity. The particle velocity of Al particles is much higher than that of Fe particles. As shown in the black circle in Figure 14b, under high-impact strength, $\mathrm{Al}$ atoms are ejected from the particles to form high-speed moving particles, passing through the Fe particles, so that part of the Fe atoms are peeled off the surface, the particles are refined and a new contact area is formed at the same time, which realizes recombination and admixture of two kinds of atoms and creates the conditions of SICR. 


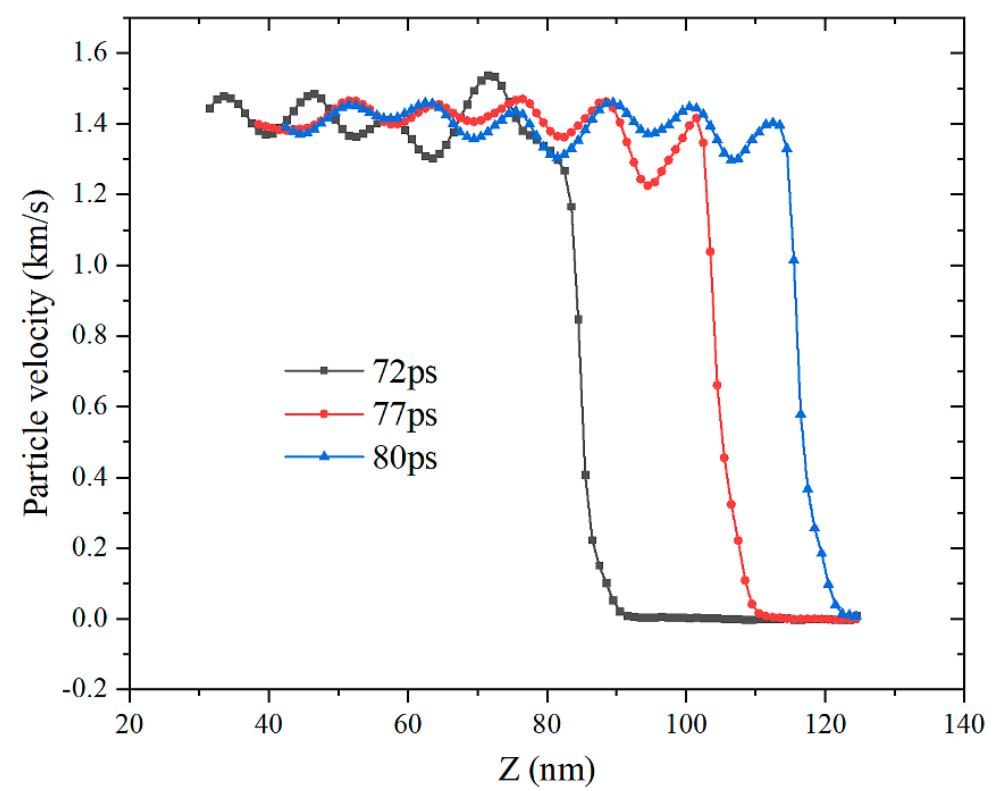

Figure 12. Distribution of particle velocity at different moments of impact velocity $(1400 \mathrm{~m} / \mathrm{s})$.

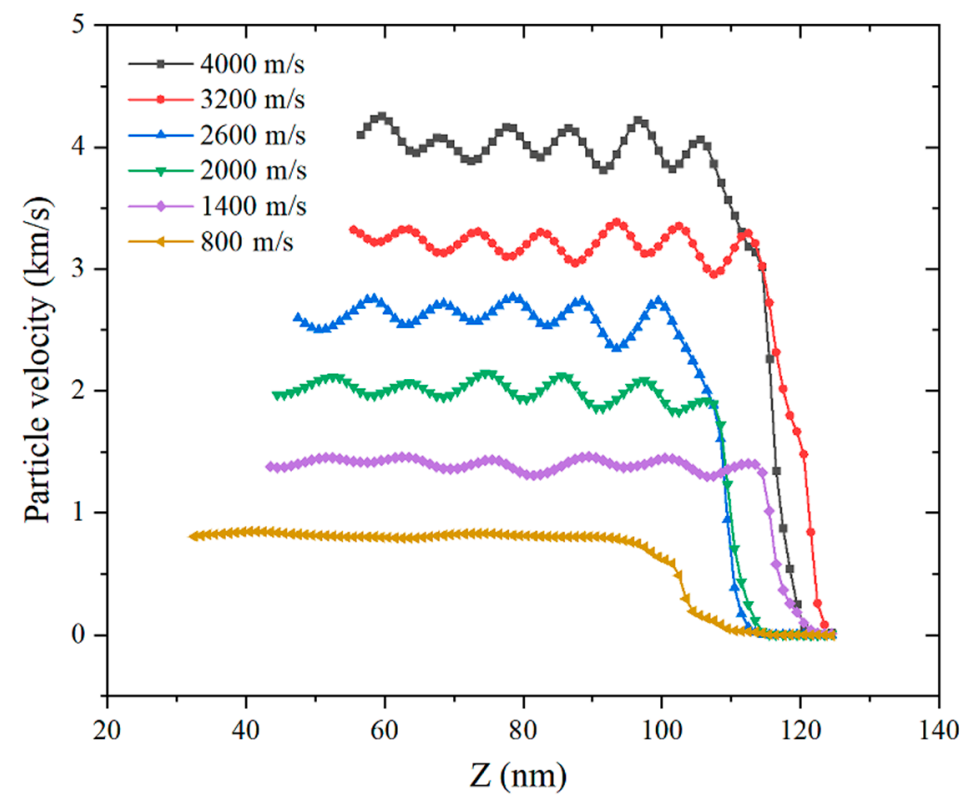

Figure 13. Comparison of particle velocities with different impact velocities.

The particles in the impact compression area collide with each other to form the average stress in the Z-axis direction, as shown in Figures 15 and 16. Compared with the particle velocity waveform diagram, the periodic oscillation of the stress waveform is weakened due to the randomness of the collision. Similar to the particle velocity waveform, as the impact velocity increases, the Z-axis stress shows a nonlinear increasing trend. The greater the impact velocity, the greater the stress increase. When the impact velocity is $4000 \mathrm{~m} / \mathrm{s}$, the instantaneous particle stress can reach $300 \mathrm{GPa}$, which has far exceeded the yield limit of the two elements. 

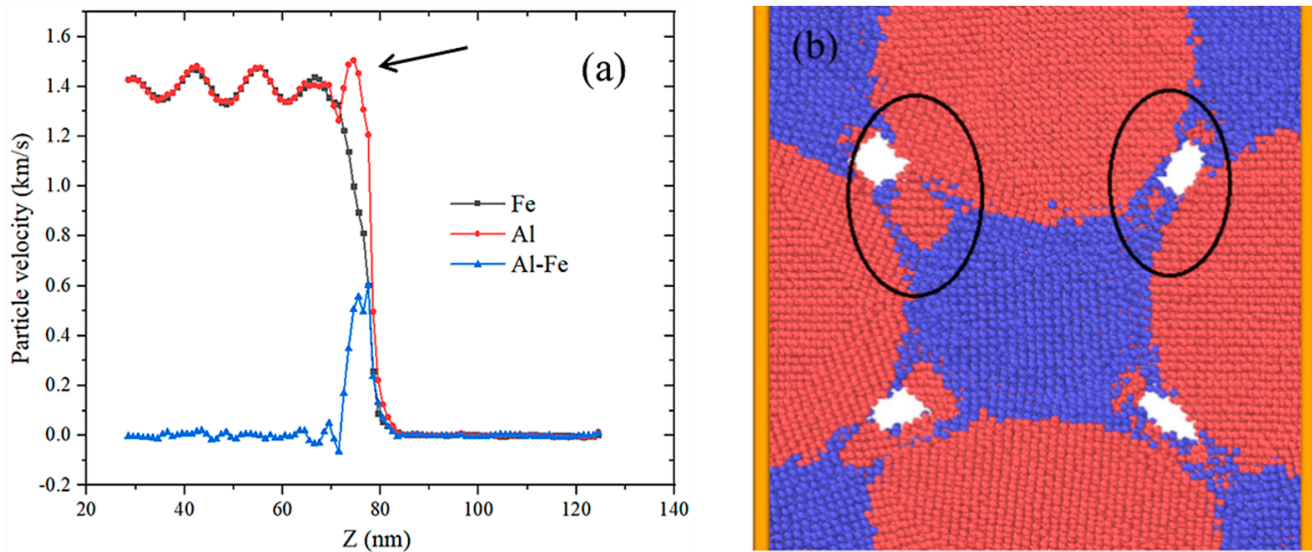

Figure 14. Velocity difference of $\mathrm{Al}$ and Fe particles: (a) comparison of the velocity of $\mathrm{Al}$ and $\mathrm{Fe}$ particles; (b) an enlarged view of the particle morphology at the arrow shown in (a).

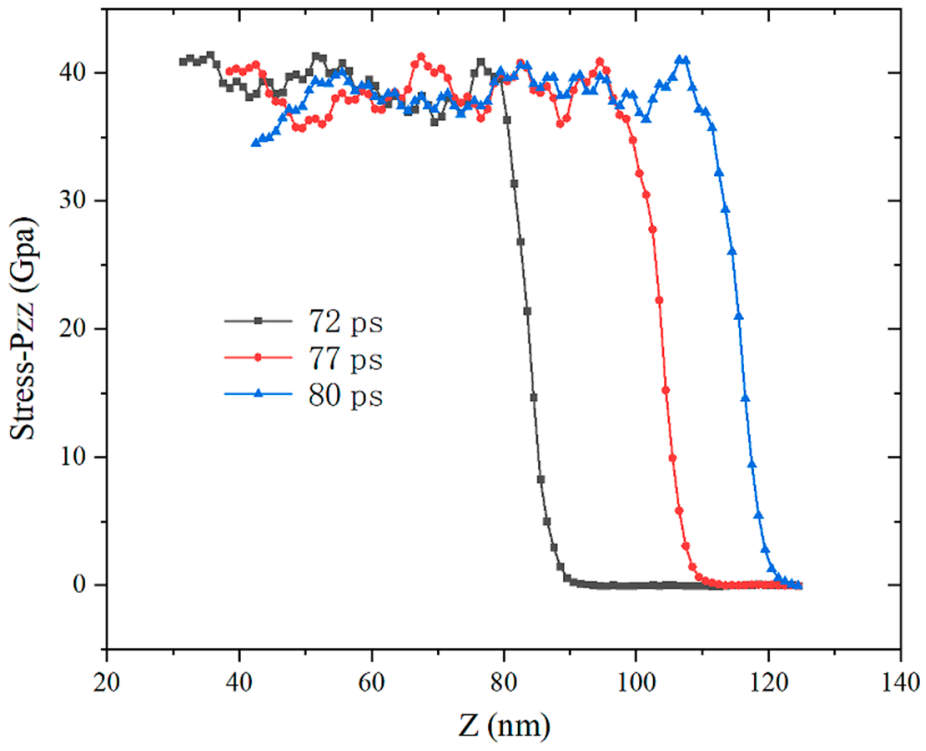

Figure 15. Impact velocity $1400 \mathrm{~m} / \mathrm{s}$ stress waveform at different moments.

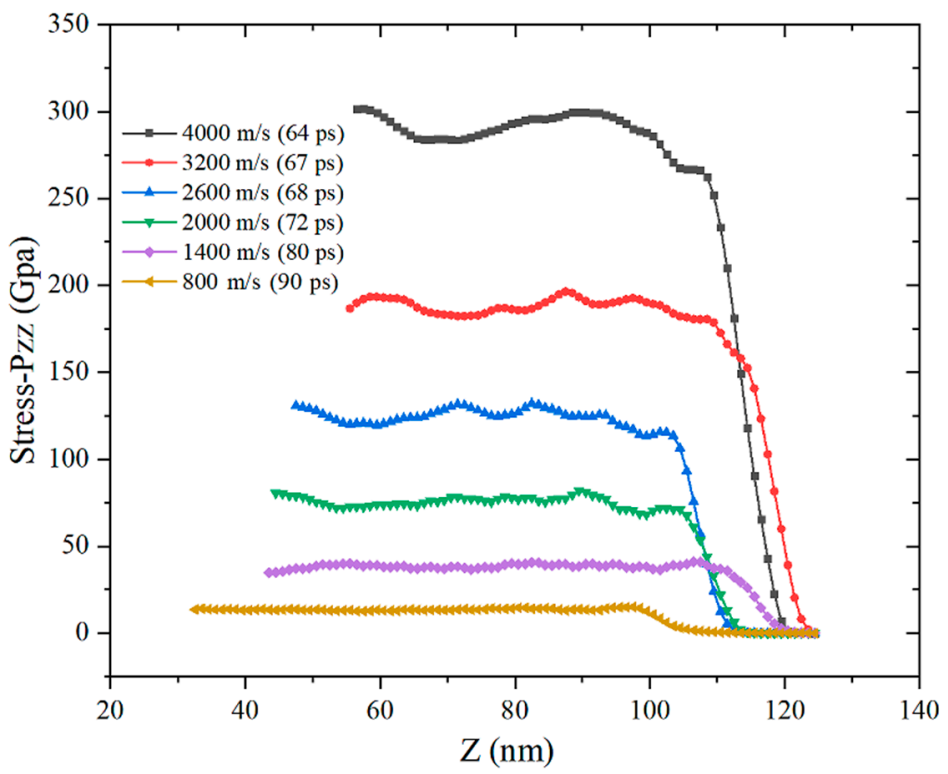

Figure 16. Stress waveforms at different impact speeds. 


\subsection{Thermal Effect}

When the material is subjected to impact loading, the temperature rise caused by the impact, the plastic deformation and the chemical reaction occur and the three cause the temperature rise of the system. It can be seen from Figures 17 and 18 that, when the impact velocity is 400 and $800 \mathrm{~m} / \mathrm{s}$, as the shock wave propagates in the Z-axis direction, the temperature distribution remains straight, basically unchanged. It shows that, under the condition of impact strength below $800 \mathrm{~m} / \mathrm{s}$, the particles in the impacted area repeat the same plastic deformation temperature rise only due to impact compression and no chemical reaction is induced. When the impact velocity is 1400 and $2000 \mathrm{~m} / \mathrm{s}$, the temperature distribution fluctuates violently, which indicates that the temperature of the system rises rapidly due to the exothermic reaction of the impact model, showing obvious SICR characteristics.

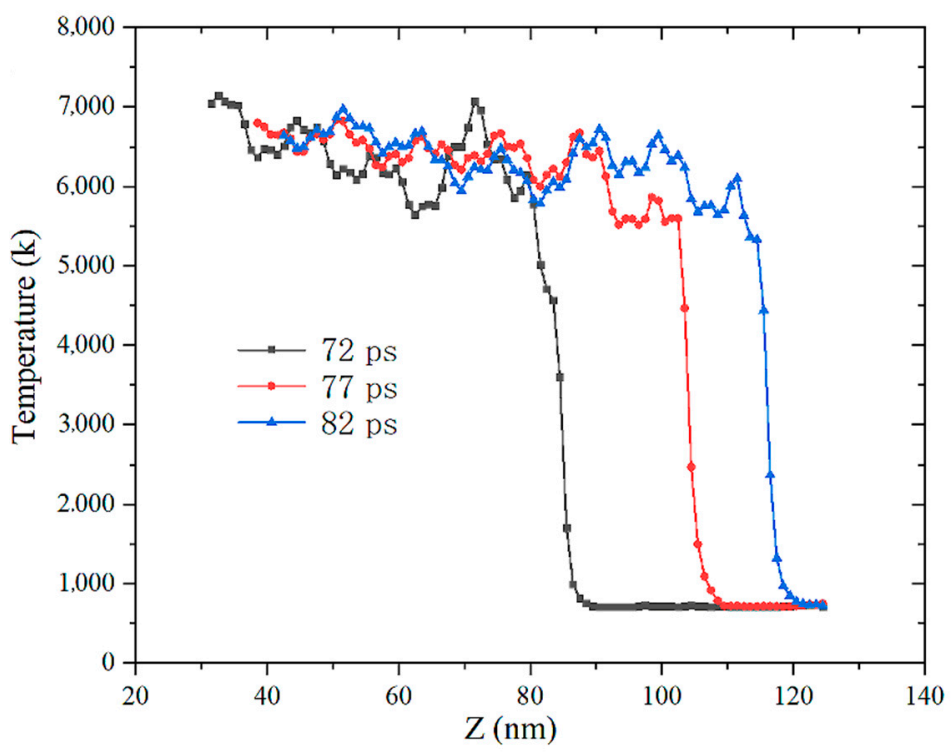

Figure 17. Temperature distribution at $1400 \mathrm{~m} / \mathrm{s}$ impact velocity.

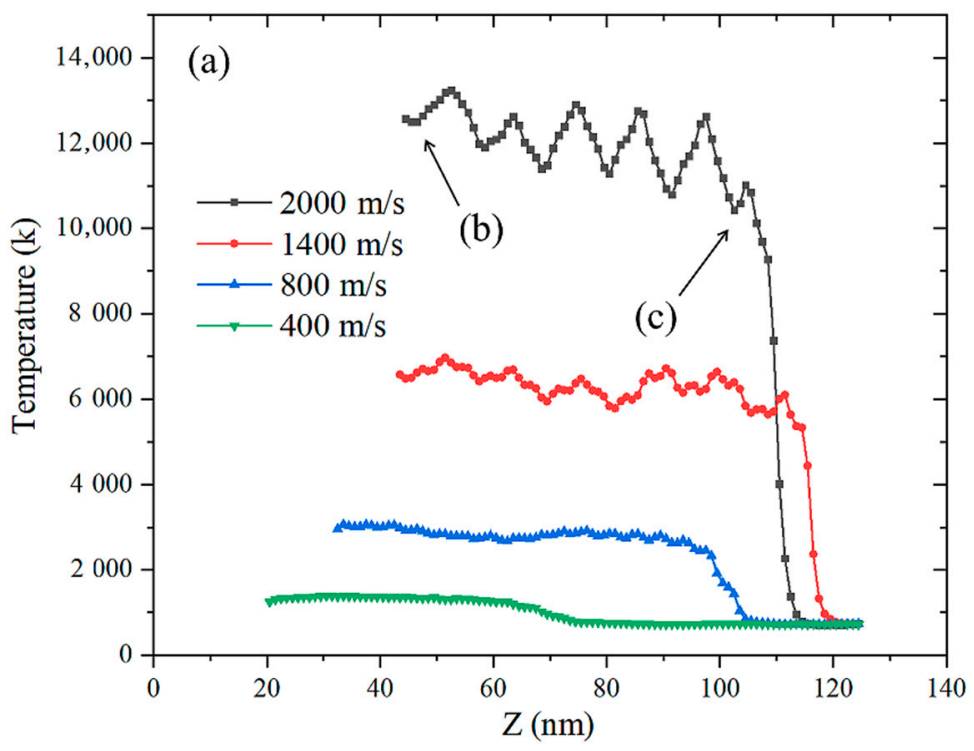

Figure 18. Cont. 

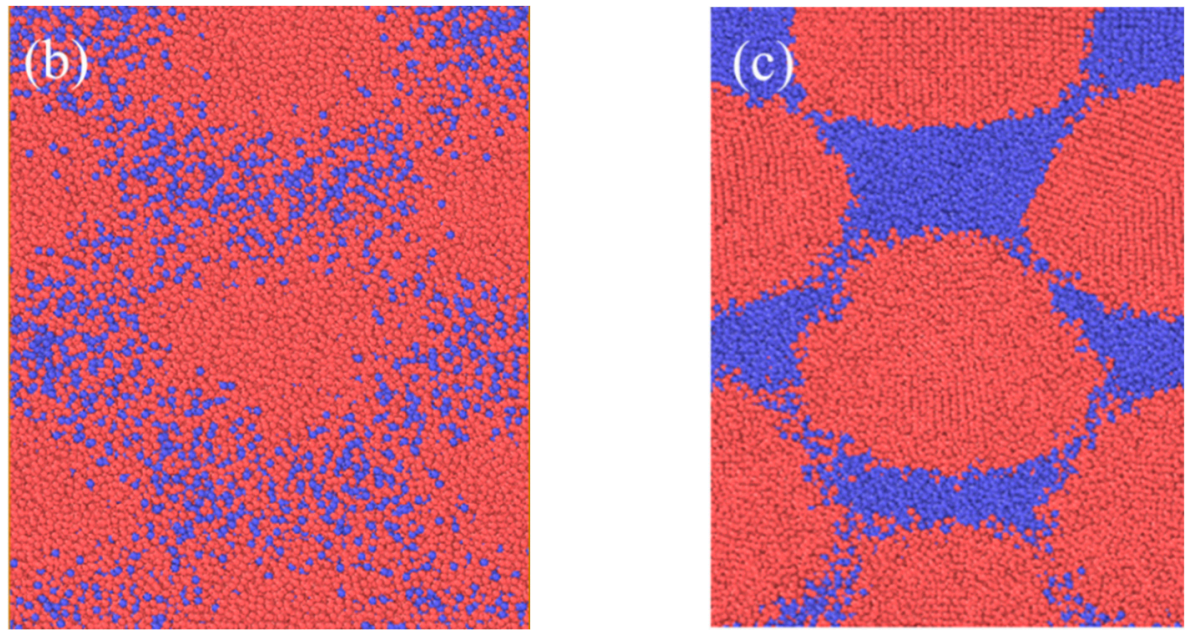

Figure 18. Temperature distribution at different impact speeds: (a) is the temperature distribution of the particles; $(\mathbf{b}, \mathbf{c})$ is the enlarged particle morphology of the arrows in (a).

\subsection{Analysis of Impact Energy-Release Mechanism}

Comparing the phenomenon of the $\mathrm{Fe}-\mathrm{Al}$ energetic jet macroscopic impact energyrelease experiment and the microscopic molecular-dynamics simulation results, it can be found that, as the impact strength increases, the impact induced reactivity of the $\mathrm{Fe}-\mathrm{Al}$ energetic jet increases, but there is an impact strength threshold, which makes the energy released by the energetic jet reach the upper limit. According to the XRD analysis of the recovered product, it is speculated that the oxidation reaction of $\mathrm{Al}$ and the compound reaction between $\mathrm{Al}$ and $\mathrm{Fe}$ mainly occur under low-impact strength and the oxidation reaction of $\mathrm{Fe}$ and thermite reaction occur under high-impact strength. Through micromolecular-dynamics simulation, it is found that only Al particles are disordered and amorphized under low-impact strength. The ejecta of Al fills the gaps between the particles and increases the contact area. Therefore, $\mathrm{Al}$ takes the lead in the oxidation reaction. The Fe particles maintain the original BCC structure and are surrounded by molten Al particles, resulting in a small amount of intermetallic reaction. When the $\mathrm{Fe}-\mathrm{Al}$ energetic jet is loaded with high-impact strength, $\mathrm{Al}$ particles and Fe particles are completely disordered and amorphized in a high temperature and high-pressure environment and fully mixed and penetrated, which greatly improves the reaction rate. At the same time, the Fe particles are further refined (the surface oxide layer may be broken), exposing a new surface and being oxidized again. Due to the full contact with $\mathrm{Al}$ atoms, the temperature exceeds $1500 \mathrm{~K}$, which induces a violent thermite reaction. Through the above analysis, it can be found that the conclusions obtained by the microscopic simulation are completely consistent with the results of the macroscopic phenomenon and meso-component analysis, revealing the mechanism of the $\mathrm{Fe}-\mathrm{Al}$ energetic jet impact-induced reaction from a multi-scale perspective, as shown in Figure 19. 


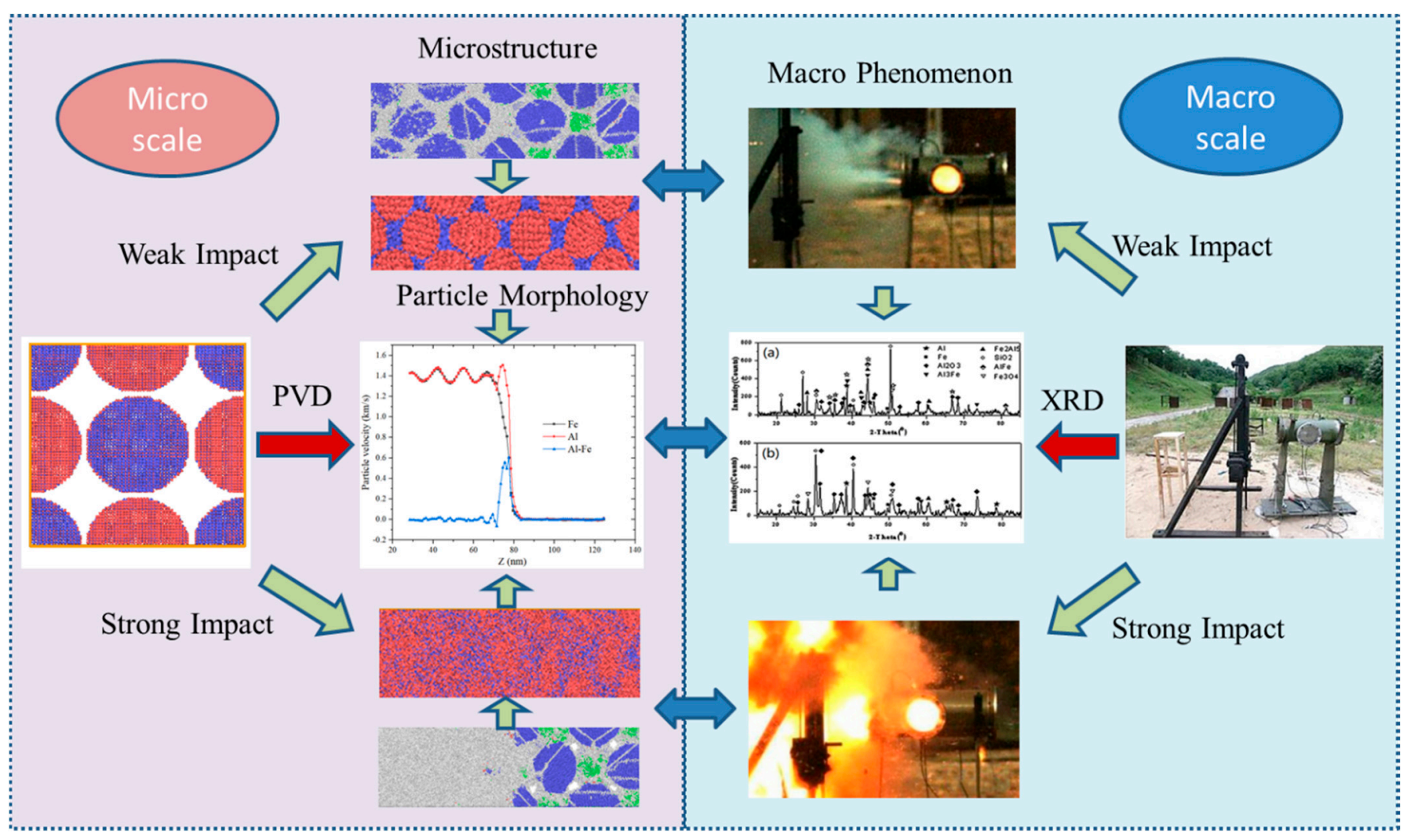

Figure 19. Mechanism of $\mathrm{Fe}-\mathrm{Al}$ energetic jet induced reaction.

\section{Conclusions}

In this paper, macroscopic experiments and microscopic molecular-dynamics simulation studies on the energy-release characteristics of $\mathrm{Fe}-\mathrm{Al}$ energetic jets under impact loading were carried out. A macroscopic dynamic energy acquisition test system was established to quantitatively acquire the overpressure formed by the energy released by the $\mathrm{Fe}-\mathrm{Al}$ energetic jet. A molecular impact model of Fe-Al particles was established and the microstructure evolution and impact thermodynamic response of $\mathrm{Fe}-\mathrm{Al}$ particles under impact loading were analysed. Comparing with the results of macroscopic experiments, microstructure analysis and microscopic simulation, the mechanism of the $\mathrm{Fe}-\mathrm{Al}$ energetic jet multi-scale impact-induced reaction was discussed. The following specific conclusions can be drawn:

(1) The reactivity of the $\mathrm{Fe}-\mathrm{Al}$ energetic jet is related to the impact strength. As the impact strength increases, the energy release of the jet increases. There is an impact strength threshold, which makes the energy released by the jet reach the upper limit, and the maximum response rate is $95.3 \%$.

(2) When the high-temperature jet forms and does not touch the target plate, the $\mathrm{Al}$ and Fe particles are squeezed and deformed and atom penetration of different elements appears at the boundary, forming uneven local stress at the GPa level and a large number of lattice defects are generated at the same time.

(3) The speed difference between $\mathrm{Fe}$ and $\mathrm{Al}$ atoms is formed at the shock wave front. High-speed $\mathrm{Al}$ atoms are ejected from the particles and pass through the Fe particles, causing part of the Fe atoms to peel off from the surface. The particles are refined and a new contact area is formed at the same time. The alternate recombination of the two kinds of atom creates conditions for impact-induced reactions.

(4) When the impact strength is low, the temperature distribution along the Z-axis of the model remains a straight line, indicating that the particles in the impact area only repeat the same plastic deformation temperature rise due to impact compression. 
When the impact strength is high, the temperature distribution fluctuates violently, which indicates that the temperature of the system rises rapidly due to the exothermic reaction of the impact model, showing obvious SICR characteristics.

(5) The mechanism of the $\mathrm{Fe}-\mathrm{Al}$ energetic jet impact-induced reaction is as follows: Under low-impact strength, only Al particles become disordered and amorphous, which increases the contact area, and $\mathrm{Al}$ undergoes an oxidation reaction. By comparison, the Fe particles maintain the original BCC structure and are surrounded by molten $\mathrm{Al}$ particles, resulting in a small amount of intermetallic chemical reaction. With high-impact strength, $\mathrm{Al}$ particles and Fe particles are completely disordered and amorphized in a high temperature and high-pressure environment and fully mixed and penetrated. The temperature of the particles exceeds $1500 \mathrm{~K}$, which induces a violent thermite reaction.

Author Contributions: Q.L., conceptualization and writing—original draft, primary author, performed most of the measurements and analysis in this manuscript; C.J., writing-review and editing; Y.D., methodology, assisted in experimental design and testing. All authors have read and agreed to the published version of the manuscript.

Funding: This work was supported by the Science and Technology Innovation Project of Colleges and Universities in Shanxi Province (grant number 2020L0297).

Institutional Review Board Statement: Not applicable.

Data Availability Statement: Due to privacy or moral restrictions, the data is not publicly available.

Acknowledgments: We acknowledge the Key Laboratory of Science and Technology on Materials under Shock and Impact for use of their electron microscopy, EDX and X-ray diffraction equipment.

Conflicts of Interest: The authors declare no competing interests.

\section{References}

1. Wang, H.; Xie, J.; Ge, C.; Guo, H.-G.; Zheng, Y.-F. Experimental investigation on enhanced damage to fuel tanks by reactive projectiles impact. Def. Technol. 2020, 17, 599-608. [CrossRef]

2. Cagle, C.; Hill, K.J.; Woodruff, C.; Pantoya, M.L.; Abraham, J.; Casey, M. Target penetration and impact analysis of intermetallic projectiles. Int. J. Impact Eng. 2019, 136, 103427. [CrossRef]

3. Yuan, T. Study on Shock-Induced Chemical Reaction Characteristics of PTFE-Based Energetic Mayerials; Beijing Institue of Technology: Beijing, China, 2019.

4. Wang, X. Study on Preparation and Performance of Fe/Al Reactive Material Liner; Beijing Institue of Technology: Beijing, China, 2016.

5. Izadi, S.; Janghorban, K.; Akbari, G.H.; Ghfari, M.; Salahinejad, E. Effects of boron addition on mechanical alloying and ordering behaviors of Fe-Al-(B) alloy powders. J. Alloys Compd. 2010, 493, 645-648. [CrossRef]

6. Kang, X.; Wang, J.; Chi, Y.; Ge, Y.; Tan, P.; Xu, Z. Research on the preoxidation performance of $\mathrm{Fe}_{3} \mathrm{Al}$ porous materials. Rare Met. Mater. Eng. 2012, 41, 822. [CrossRef]

7. Du, Y.; Li, Q. Study on Energy Release Characteristics of Fe/Al Energetic Jet. Chin. J. Explos. Propellants 2018, 41, 594-598. [CrossRef]

8. Baker, E.L.; Daniels, A.S.; Ng, K.W.; Martin, V.O.; Orosz, J.P. Barnie: A unitary demolition warhead. In Proceedings of the 19th International Symposium of Ballistics, Interlaken, Switzerland, 7-11 May 2011; pp. 57-69.

9. Du, R. Study on Preparation of Fe/Alp Metal Composites; Huazhong University of Science and Technology: Wuhan, China, 2012.

10. Airiskallio, E.; Nurmi, E.; Heinonen, M.H.; Väyrynen, I.J.; Kokko, K.; Ropo, M.; Punkkinen, M.; Pitkänen, H.; Alatalo, M.; Kollár, J.; et al. High temperature oxidation of $\mathrm{Fe}-\mathrm{Al}$ and $\mathrm{Fe}-\mathrm{Cr}-\mathrm{Al}$ alloys: The role of $\mathrm{Cr}$ as a chemically active element. Corros. Sci. 2010, 52, 3394-3404. [CrossRef]

11. Wang, Y.; Jiang, W.; Zhang, X.F.; Cheng, Z.P.; An, C.W.; Guo, X.D.; Li, F.S. Preparation and characterization of composite with micron Al coating in nanometer Fe particles. J. Funct. Mater. 2004, 11, 1900-1902.

12. Wang, X.Y.; Wang, Y.W.; Wang, Z.C.; Jiang, C.L.; Li, Q. Effect of composition and sintering temperature on reaction heat of Fe-Al reactive material. Rare Met. Mater. Eng. 2017, 46, 3043-3047.

13. Andryushchehko, V.A.; Bavol, O.V.; Khvatov, T.; Garan, A.C.; Mekhed, O.A. Impact of pulse laser action on surface of samples of fe-al-c alloys containing diamond crystals. Metallofiz. I Noveišhie Tekhnologii 2010, 32, 883-888.

14. Zamanzade, M.; Hasemann, G.; Motz, C.; Krüger, M.; Barnoush, A. Vacancy effects on the mechanical behavior of B2-FeAl intermetallics. Mater. Sci. Eng. A 2017, 712, 88-96. [CrossRef]

15. Guo, Y. Molecular Dynamics of the Phase Transition in Single-Crystal Al-Fe Induced by High-Pressure; Shanxi University: Taiyuan, China, 2013. 
16. Wang, K.; Xiao, S.; Deng, H.; Zhu, W.; Hu, W. An atomic study on the shock-induced plasticity and phase transition for iron-based single crystals. Int. J. Plast. 2014, 59, 180-198. [CrossRef]

17. Yang, J.; Hu, W.; Tang, J. Effect of incident energy on the configuration of fe-al nanoparticles, a molecular dynamics simulation of impact deposition. RSC Adv. 2013, 4, 2155-2160. [CrossRef]

18. Lu, Z.; Zhu, W.; Lu, T.; Wang, W. Does the fcc phase exist in the Fe bcc-hcp transition? A conclusion from first-principles studies. Model. Simul. Mater. Sci. Eng. 2014, 22, 025007. [CrossRef]

19. Huang, Y. An Atomistic Study on Shock-Compression Response in Iron-Based Single Crystal Iron with Dislocations; Hunan University: Changsha, China, 2019.

20. Gunkelmann, N.; Bringa, E.M.; Kang, K.; Ackland, G.J.; Ruestes, C.J.; Urbassek, H.M. Polycrystalline iron under compression: Plasticity and phase transitions. Phys. Rev. B 2012, 86, 144111. [CrossRef]

21. Li, Q.; Du, Y. Experimental Study on the Energy-Release Characteristics of Fine-Grained Fe/ Al Energetic Jets under Impact Loading. Materials 2019, 12, 3317. [CrossRef] [PubMed]

22. Lee, E.; Lee, B. Modified embedded-atom method interatomic potential for the Fe-Al system. J. Phys. Condens. Matter. 2010, 22, 175702:1-175702:9. [CrossRef] [PubMed]

23. Xiong, Y. Molecular Dymamic Simulation of Shock-Compression Response of Ni+Al Nanopowders; Hunan University: Changsha, China, 2013.

24. Li, Q.; Du, Y. Study of the Impact Energy Release Characteristics of Fine-Grained Fe-Al Energetic Jets. Propellants Explos. Pyrotech. 2019, 45, 445-452. [CrossRef]

25. Gorji, N.E.; O'Connor, R.; Brabazon, D. XPS, XRD, and SEM characterization of the virgin and recycled metallic powders for 3D printing applications. IOP Conf. Ser. Mater. Sci. Eng. 2019, 591, 012016. [CrossRef]

26. Siva, A.V.S.; Prasad Sumit, B. Numerical modeling of shock-induced chemical reactions (SICR) in reactive power mixtures using smoothed particle hydrodynamics (SPH). Model. Simul. Mater. Sci. Eng. 2015, 23, 075005. [CrossRef] 